\title{
SPE-UHPLC-FLD Method for the Simultaneous Determination of Five Anthraquinones in Human Urine Using Mixed-Mode Bis(tetraoxacalix[2] arene[2]triazine) Modified Silica as Sorbent
}

\author{
Kai Hu, ${ }^{1}$ Yonghui Qiao, ${ }^{1}$ Zhifen Deng, ${ }^{2}$ Mingxia Wu, ${ }^{1}$ and Wei Liu ${ }^{1}$ \\ ${ }^{1}$ Henan University of Chinese Medicine, Zhengzhou 450008, China \\ ${ }^{2}$ College of Chemistry and Molecular Engineering, Zhengzhou University, Zhengzhou 450052, China \\ Correspondence should be addressed to Kai Hu; hukaizzu@126.com
}

Received 10 March 2017; Revised 13 July 2017; Accepted 20 August 2017; Published 28 September 2017

Academic Editor: Hassan Y. Aboul Enein

Copyright (c) $2017 \mathrm{Kai} \mathrm{Hu}$ et al. This is an open access article distributed under the Creative Commons Attribution License, which permits unrestricted use, distribution, and reproduction in any medium, provided the original work is properly cited.

\begin{abstract}
The five anthraquinones compounds (including aloe-emodin, emodin, physcion, chrysophanol, and rhein) are regarded as the main effective ingredients in rhubarb (Dahuang in Chinese, one of the commonly used Chinese herbal medicines). In this work, a simple and effective solid phase extraction (SPE) method based on bis(tetraoxacalix[2]arene[2]triazine) modified silica gel as adsorbent was developed. Coupled with UHPLC-FLD, the developed method was successfully applied for the measuring of main anthraquinones in human urine after oral administration of the extracts of rhubarb. To obtain the highest recoveries of the five anthraquinones in the SPE process, the main parameters which may affect extraction efficiency were optimized. The optimized sorbent amount, sample loading $\mathrm{pH}$, sample loading rate, washing solution, and eluent condition were obtained. The developed method showed good linearity in $0.012-1.800 \mu \mathrm{g} \mathrm{mL}-1$ for the five anthraquinones with correlation coefficients more than 0.9993 . The investigated LOD values ranged from 3.9 to $5.7 \mathrm{ng} \mathrm{mL}^{-1}$, while the LOQs were between 12.0 and $18.2 \mathrm{ng} \mathrm{mL}^{-1}$. The recoveries of the method were also investigated, which were in the range of $94.8-106.6 \%$. The application of the mixed-mode SPE materials in the proposed method was feasible and simple, and suitable for the enrichment of anthraquinones in urine samples.
\end{abstract}

\section{Introduction}

As a well-known herbal medicine in China, Rhubarb has been used to treat diseases since ancient times. Among all constituents in rhubarb, the anthraquinones (including physcion, rhein, emodin, chrysophanol, and aloe-emodin) play a dominant role for the medicinal properties of rhubarb and are regarded as important active ingredients with extensive pharmacological effects such as antiviral [1], antibacterial [2], antifungal [3], antioxidant [4], antiath-erosclerotic [5], and anticancer activities [6]. Thus, the investigation on the qualitative and quantitative analysis of anthraquinones in body fluids (plasma, urine, etc.) is always a hot research area in pharmacokinetic study.

Because of the complexity of sample matrixes and the trace levels of anthraquinones in urine sample and other biological sample, there is an urgent need for developing a sensitive method for the determination of anthraquinone compounds. Until now, there are many methods that have been conducted for the determination of anthraquinone compounds, such as capillary zone electrophoresis (CZE) [7], capillary electrochromatography (CE) [8], thin layer chromatography (TLC) [9], and micellar electrokinetic chromatography (MEKC) [10, 11]. However, due to its easy operation, high accuracy, and wide applicability, HPLC is still most widely used among these techniques [12-18]. On the other hand, many extraction methods, such as decocting or refluxing extraction [19, 20], liquid-liquid extraction [21], and ultrasonic extraction [22], have been widely applied for the enrichment and cleanup of trace anthraquinones in the complex biological and herbs samples. However, some of these methods are usually time-consuming, solvents, or laborintensive. Due to its simplicity and low solvent consumption, solid phase extraction (SPE) methods $[8,12,13]$ have emerged as effective alternatives for sample preparation method. However, the traditional reversed phase or ion-exchange sorbents 
are usually showing indiscriminate adsorption effects, resulting in a large number of matrix interferences, which may seriously affect the accuracy of the measurement. Therefore, it is necessary to establish an effective sample preparation method for the analysis of anthraquinones compounds in complicated body fluids samples.

Calixarene is a typical representative of the third-generation host molecule following crown ether and cyclodextrin. By modifying them onto the surface of silica gel, calixarenes have been widely studied as solid phase extraction and stationary phase materials. Due to the peculiar structural characteristics of cavity-shape and benzene ring skeleton, these materials can offer varieties of interaction with analytes, such as hydrophobic, hydrogen bonding, $\pi-\pi$, as well as inclusion interaction [23-31]. Nowadays, heterocyclic calixarene appeared as a novel kind of supramolecular compound [32]. Being different from traditional calixarene, heterocyclic calixarene is usually constituted of benzene rings and triazine rings connected by $\mathrm{O}$ or $\mathrm{NH}$ groups, which can not only manipulate the cavity, but also improve their recognizing selectivity toward a great diversity of guest species. Recently, by modifying bis(tetraoxacalix[2] arene[2]triazine) onto the surface of silica gel, a new separation material was successfully used as stationary phase and solid extraction material $[33,34]$. The new separation material was exhibiting multiple-interaction and mixed-mode separation mechanisms, and excellent extraction ability toward flavonoids compound [33, 34]. As anthraquinones have similar molecular structures with flavonoids compound, excellent extraction capacity toward anthraquinone compounds by using the same sorbents is anticipated. Thus, in this study, the new material was utilized as new solid phase extraction material for enrichment and cleanup of anthraquinone compounds in the human urine.

In the present study, a novel bis(tetraoxacalix[2]arene[2]triazine) sorbent (BTO-SPE) was employed to develop a high-efficiency and reliable sample preparation procedure for the analysis of anthraquinone compounds in the human urine. All the main factors affecting SPE process were optimized to obtain the high recoveries. Based on BTOSPE sorbents as solid phase extraction materials, a UHPLCFLD method was developed and evaluated. The analysis results showed that it was appropriate for the enrichment and cleanup of anthraquinone compounds in the urine and other complex biological samples.

\section{Materials and Methods}

2.1. Chemicals, Materials, and Solutions. The reference standards of chrysophanol, physcion, rhein, aloe-emodin, and emodin were provided by the National Institutes for Food and Drug Control (Beijing, China) (Figure 1). HPLC-grade acetonitrile, methanol $(\mathrm{MeOH})$, and formic acid were purchased from Sigma-Aldrich Co. All other chemicals and reagents used were of analytical grade obtained from Shanghai Aladdin Chemical Reagent Company. The Polypropylene SPE tube $(3 \mathrm{~mL})$ used for packing the sorbent and the PE Frit $(20 \mu \mathrm{m})$ were all obtained from Shanghai ANPEL Laboratory Technologies. The water used for HPLC system and SPE process was prepared by using a Millipore Milli-Q system (Bedford, MA, USA). Silica gels (particle size of $40-60 \mu \mathrm{m}$, surface area of $500 \mathrm{~m}^{2} \mathrm{~g}^{-1}$ ) were supplied by Shanghai Aladdin Chemical Reagent Company. The commercialized C18 SPE columns (100 mg, $3 \mathrm{~mL}$ ) were provided by the company of Waters (Milford, MA, USA), which were used as comparison with self-made BTO-SPE.

By dissolving the reference standards into $\mathrm{MeOH}$, the stock solutions of chrysophanol, rhein, physcion, aloeemodin, and emodin were prepared at concentrations of $1 \mathrm{mg} \mathrm{mL}{ }^{-1}$, respectively. Then, the stock solutions were mixed and diluted with $0.1 \%$ phosphoric acid water/methanol solution $(50: 50, \mathrm{v} / \mathrm{v})$ to prepare working solutions. All the prepared stock solutions and working solutions were stored in a refrigerator at $4^{\circ} \mathrm{C}$ ready for use.

2.2. Instruments and Measurement. All separation was performed using an Agilent UHPLC configured with a binary pump (G4220B), a column compartment (G1316C), a FLD detector (G1321B), and an autosampler (G4226A). Elemental analysis was carried out on an EA 2400 elemental analyzer (PerkinElmer Corporation), and IR spectra were obtained by using a Nicolet iS5 FT-IR analyzer (Thermo Scientific). A centrifuge (Refrigerated Centrifuge XT, Thermo Scientific) and a Vortex mixer (Lab Dancer, IKA) were used for the centrifugal separation and thorough mixing of sample solutions.

The UHPLC chromatographic separation was carried out by using a Zorbax SB-C18 column (Agilent, 3.0 $\times$ $50 \mathrm{~mm}, 1.8 \mu \mathrm{m})$ with mobile phase A $(0.1 \%$ phosphoric acid water, $\mathrm{v} / \mathrm{v})$ and mobile phase $\mathrm{B}(\mathrm{MeOH})$ at the flow rate of $0.5 \mathrm{~mL} \mathrm{~min}^{-1}$. After careful optimization, the HPLC gradient eluent program was set. The detailed procedures were as follows: $0-1 \mathrm{~min}, 55 \% \mathrm{~B}$; $1-4 \mathrm{~min}, 55 \%-70 \% \mathrm{~B} ; 4-9 \mathrm{~min}$, $70 \%-90 \%$ B; 9-9.5 min $90 \%-100 \%$ B; $9.5-10$ min $100 \%$ B. The analysis temperature and injection volume were set at $30^{\circ} \mathrm{C}$ and $5 \mu \mathrm{L}$, respectively. The excitation and emission wavelengths of fluorescence detection were set at $435 \mathrm{~nm}$ and $515 \mathrm{~nm}$, respectively.

2.3. The Synthesis of BTO-SPE. The two-step preparation procedure of BTO-SPE sorbent was according the previous methods $[33,34]$ and illustrated in Figure 2. As can be seen from Figure 2, after 3-aminopropyl bonded silica gel (APS) was prepared; the mixture of APS, bis(tetraoxacalix[2]arene[2]triazine) and the reagent of tetrahydrofuran (anhydrous) were stirred in the stream of $\mathrm{N}_{2}$ for another $24 \mathrm{~h}$. The final BTO-SPE was obtained by filtration through a G5 filter and washed by using methanol, water, and acetone.

2.4. Preparation of Urine Sample and SPE Procedures. Urine sample $(1 \mathrm{~mL})$ was piped into a centrifuge tube, and $1 \mathrm{~mL}$ $\mathrm{MeOH}$ was added. After being shaken quickly for $5 \mathrm{~min}$, the above tube was then centrifuged at $12,000 \mathrm{rpm}$ at $4^{\circ} \mathrm{C}$ for $15 \mathrm{~min}$. After the supernatant was collected carefully, $1 \mathrm{~mL}$ $0.1 \%$ phosphoric acid was added to dilute the solution, mixed by a Vortex mixer, and the mixture was ready to load onto SPE cartridge for the further enrichment and purification.

BTO-SPE (100 mg) was accurate weighed and filled into an empty cartridge $(3 \mathrm{~mL})$; a PE Frit $(20 \mu \mathrm{m})$ was placed above and below the sorbent, respectively, to prevent the 
<smiles>O=C1c2cc(CO)cc(O)c2C(=O)C2C(O)=CC=CC12</smiles>

Aloe-emodin

$(\mathrm{p} K \mathrm{a}=8.49)$<smiles>Cc1cc(O)c2c(c1)C(=O)C1C=C(O)C=C(O)C1C2=O</smiles>

Emodin

$(\mathrm{pKa}=5.70,7.92)$<smiles>COC1=CC2C(=O)c3cc(C)cc(O)c3C(=O)C2C(O)=C1</smiles>

Physcion $(\mathrm{p} K \mathrm{a}=8.49)$<smiles>O=C(O)c1cc(O)c2c(c1)C(=O)C1C=CC=C(O)C1C2=O</smiles>

$(\mathrm{pKa}=4.51,8.41)$<smiles>CC1=CC2C(=O)c3cccc(O)c3C(=O)C2C(O)=C1</smiles>

Chrysophanol

$(\mathrm{p} K \mathrm{a}=8.51)$

Figure 1: The chemical structures and $\mathrm{pKa}$ values of the studied anthraquinones.

loss of sorbent. Then, the applicability of the prepared cartridge for the enrichment of anthraquinone in human urine was investigated. In brief, after the cartridge was activated by treatment with $\mathrm{MeOH}(3 \mathrm{~mL})$ and water $(3 \mathrm{~mL}), 1 \mathrm{~mL}$ treated urine sample spiked with analytes was flowed through the BTO-SPE cartridge by gravity. The SPE cartridge was carefully flushed by $\mathrm{MeOH} /$ water solution $(2 \mathrm{~mL}, 5 \%$, v/v) and eluted by methanol $(2 \mathrm{~mL})$. The eluent was evaporated to dryness at $35^{\circ} \mathrm{C}$ under a gentle $\mathrm{N}_{2}$ stream and then redissolved into $100 \mu \mathrm{L} 0.1 \%$ phosphoric acid water/methanol solution $(50: 50, \mathrm{v} / \mathrm{v})$. After filtration through a $0.22 \mu \mathrm{m}$ Nylon filter (Waters, USA), the redissolved solution was ready for UHPLC-FLD analysis.

\section{Results and Discussion}

3.1. Characterization of BTO-SPE Sorbents. Infrared spectra of APS and BTO-SPE were shown in Figure 3. Compared with the two spectra, the new absorption peaks of 1597, 1502, and $1453 \mathrm{~cm}^{-1}$ were observed in BTO-SPE's spectrum, which may be all caused by the $\mathrm{C}-\mathrm{C}$ stretch vibration of benzene ring skeleton. These significant differences indicate that the heterocyclic calixarene of bis(tetraoxacalix[2] arene[2]triazine) was successfully bonded onto the surface of microsphere.

Firstly, quantitative characterization of APS and BTOSPE was conducted by the measure of elemental analysis. The content of $\mathrm{C}, \mathrm{H}$, and $\mathrm{N}$ between APS and BTO-SPE varied a lot. As the result showed, the $\mathrm{C}, \mathrm{H}$, and $\mathrm{N}$ in BTO-SPE were $12.87 \%, 1.38 \%$, and $5.35 \%$, respectively. The values were higher than those of APS (the content of $\mathrm{C}, \mathrm{H}$, and $\mathrm{N}$ accounted for $4.72 \%, 1.15 \%$, and $1.29 \%$, resp.), indicating bis(tetraoxacalix[2]arene[2]triazine) was successfully modified onto the surface of silica gel. According to the change of carbon content, the amount of bis(tetraoxacalix[2]arene[2]triazine) onto the surface of silica gel can be calculated as $323 \mu \mathrm{mol} \mathrm{g}^{-1}$. 


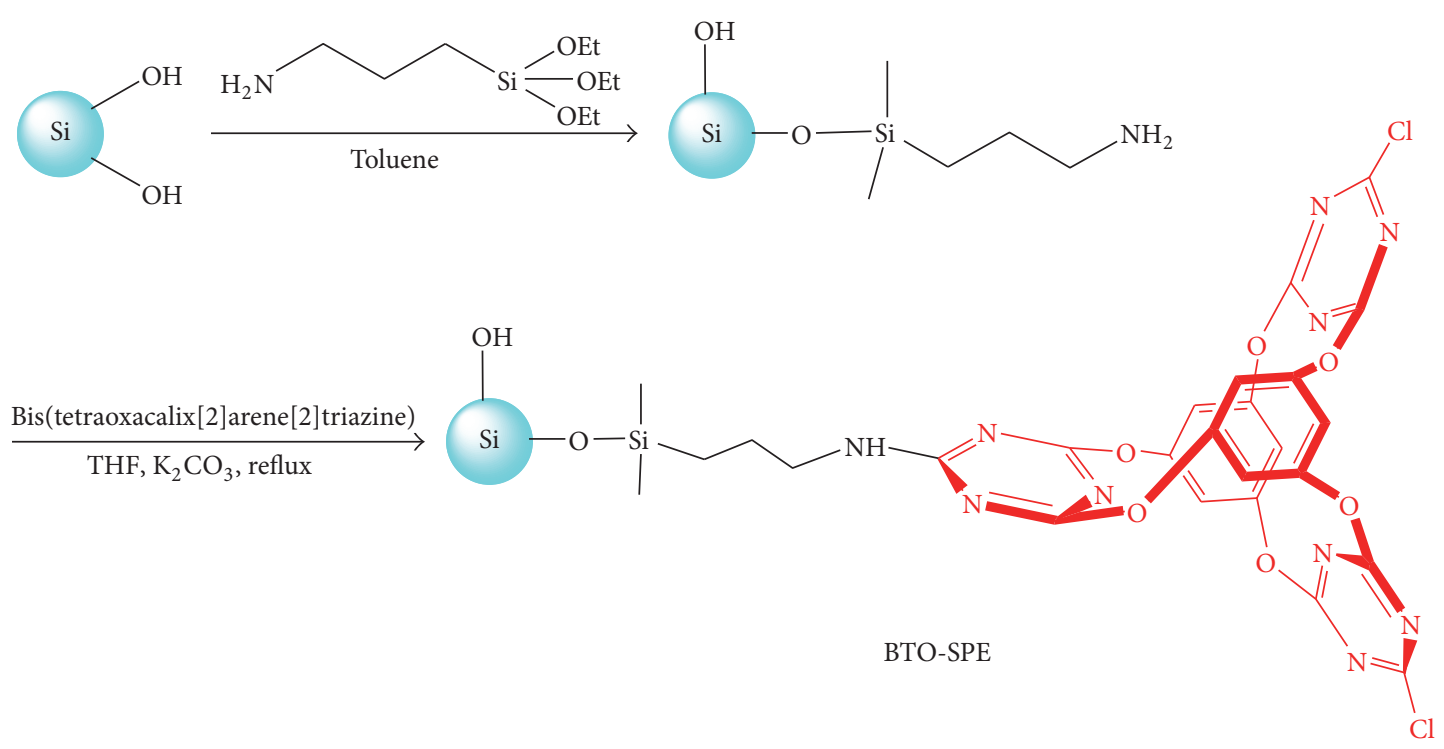

FIGURE 2: Preparation scheme of bis(tetraoxacalix[2] arene[2]triazine)-modified silica gel SPE sorbent (BTO-SPE).

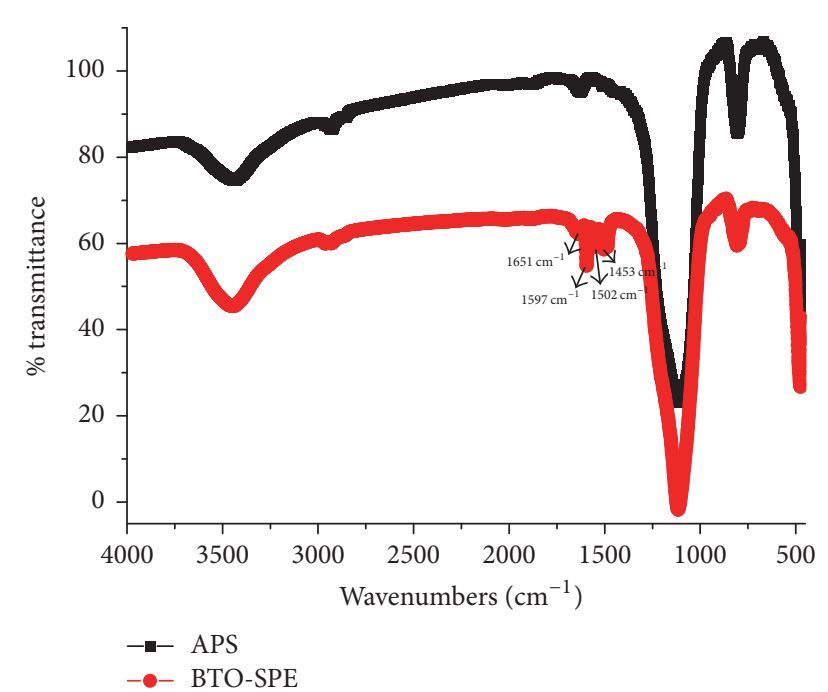

FigURE 3: IR spectra of APS and BTO-SPE sorbent.

3.2. SPE Optimization. In this study, to achieve maximum adsorption efficiency in the SPE process, the effect of the main factors affecting the recoveries $(n=3)$ of anthraquinones was evaluated.

3.2.1. The Amount of Sorbent. The sorbent amount in the SPE cartridge is closely related to its purification effect. In this section, the influence of sorbent amount on the extraction recoveries of anthraquinones $(1 \mathrm{~mL}$ working aqueous solution, $0.5 \mu \mathrm{g} \mathrm{mL}^{-1}$ ) was studied. As can be seen from Figure 4 , the recoveries of anthraquinones were increased with the amount of sorbent increased from 20 to $100 \mathrm{mg}$, and no significant difference of the recoveries was observed with the sorbent amount from 100 to $120 \mathrm{mg}$. Therefore, it can be inferred that $100 \mathrm{mg}$ of BTO-SPE was sufficient to obtain satisfactory extraction recoveries and purification efficiency

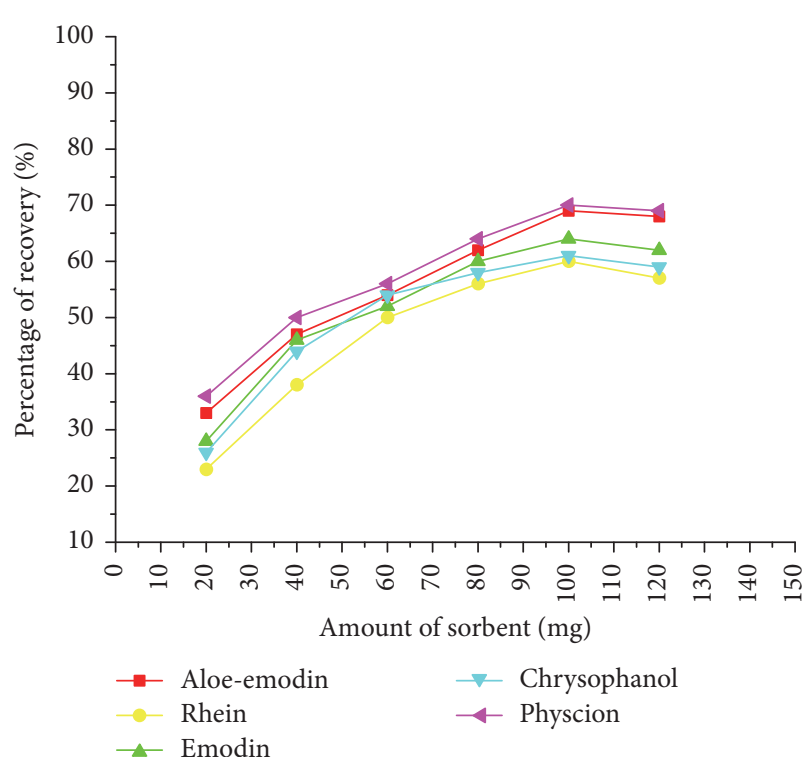

FIGURE 4: Effect of BTO-SPE sorbent amount on the recovery of anthraquinones.

for anthraquinones. Thus, the optimal amount of the sorbent was selected as $100 \mathrm{mg}$ in the study.

3.2.2. The Effect of Sample Loading $p H$. As anthraquinones have many hydroxyl groups, they may present in different states with the adjustment of $\mathrm{pH}$ medium; the SPE of anthraquinones probably seriously relies on the sample $\mathrm{pH}$. Moreover, sample loading $\mathrm{pH}$ can also influence the solubility of the target acidic/basic solutes. Thus, in this section, the effect of sample loading $\mathrm{pH}$ (in the range of 3 to 10) on the extraction recoveries was studied. It can be observed from Figure 5 that the sample loading $\mathrm{pH}$ had a strong impact on the extraction recoveries of the target anthraquinones. 


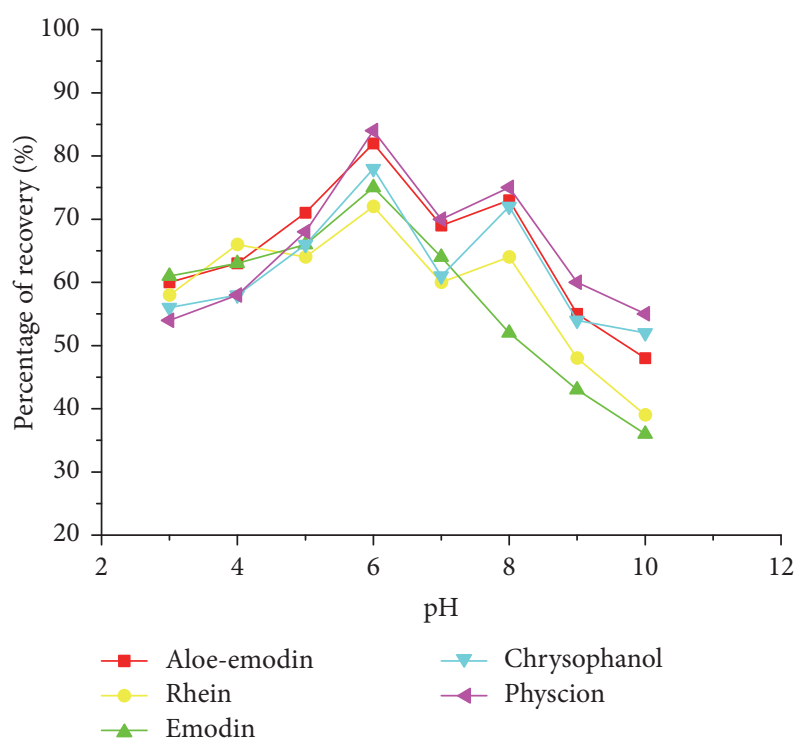

FIGURE 5: Effect of sample $\mathrm{pH}$ on the recovery of anthraquinones.

The highest extraction recoveries were obtained at $\mathrm{pH}$ 6 , with the recoveries of $78 \%, 72 \%, 75 \%, 82 \%$, and $84 \%$ for chrysophanol, rhein, emodin, aloe-emodin, and physcion, respectively. Therefore, pH 6 was selected as the optimal $\mathrm{pH}$ value for following extraction process. The reason for the optimized results can be attributed to the protonated or deprotonated states of anthraquinones compounds. As anthraquinones have many hydroxyl groups, they may exist in the form of protonated format in lower $\mathrm{pH}$ value and deprotonated format in basic $\mathrm{pH}$ solution. However, it is difficult for the reversed-phase material to strongly absorb the hydrophilic guest (protonated or deprotonated). Moreover, it can weaken the hydrogen bonding interaction between the target anthraquinones (protonated or deprotonated) and heterocyclic calixarene with the change of $\mathrm{pH}$ values in the sample loading solution. On the other hand, anion exchange interaction may also enhance the absorption interaction when the $\mathrm{pH}$ conditions were higher than those of the analytes' $\mathrm{pKa}$ values. Thus, the deprotonated rhein and emodin can have higher recoveries during the extraction procedure at $\mathrm{pH}$ 6. Therefore, the sample was adjusted to $\mathrm{pH} 6$ in the following extraction process.

3.2.3. Flow Rate of the Sample. The sample loading flow rate was an important factor that affected both the extraction recoveries and the sample preparation time. Under controlled negative pressures, the sample loading rate was optimized between 0.5 and $2 \mathrm{~mL} \mathrm{~min}^{-1}$. As a result, no distinct variance on the extraction recoveries of target anthraquinones was discovered by changing the flow rates of sample. As the volume of the sample was only $1 \mathrm{~mL}$, it only took less than 2 min to pass through the SPE cartridge by gravity, so the sample loading rate almost has no effect on the extraction recoveries and extraction time. Thus, we did not control the sample loading rate and let the sample pass through the SPE cartridge by gravity.

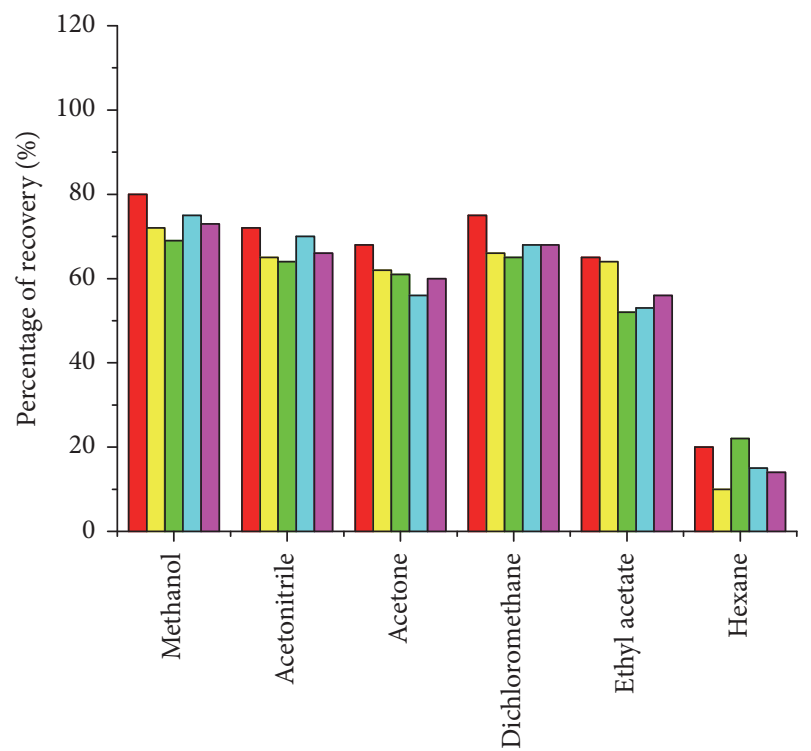

Types of eluting solvent

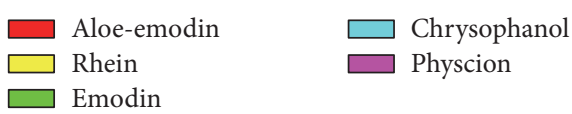

Figure 6: Effect of eluting solvent on recovery of anthraquinones.

3.2.4. The Elution Step. In order to eluate the target analytes in the solid phase extraction process, it is of great importance to select a suitable eluting solution. In this section, six eluting solutions of different polarities, including methanol, acetone, acetonitrile, ethylacetate, dichloromethane, and hexane, were introduced to acquire the most appropriate elution solution. As shown in Figure 6, by using the polar elution solvents (such as methanol, acetonitrile, and acetone), high recoveries were obtained compared with that of nonpolar solvents (such as dichloromethane, hexane, and ethyl acetate), which may be attributed to the fact that elution solvents with strong polarities can displace the target analytes in very little volume from the sorbent. As can be seen from Figure 6, hexane showed poor elution capability toward all the studied anthraquinones, indicating BTO-SPE sorbent had strong adsorption capacity toward anthraquinones compounds. Moreover, among all the elution solvent, highest extraction recoveries for all the investigated anthraquinone compounds were acquired by using methanol. Thus, in the following extraction experiments, methanol was selected as the most suitable elution solution.

The volume of eluent was investigated in the range of $0.5-5 \mathrm{~mL}$. With the volume of $\mathrm{MeOH}$ increased from 0.5 to $2 \mathrm{~mL}$, the extraction recoveries of anthraquinones compounds increased. However, with the volume increased from 2 to $5 \mathrm{~mL}$, the recoveries were slightly decreased. The possible reason can be ascribed to the dilution of sample and the loss in the process of nitrogen blowing process. Therefore, the volume of eluent of methanol was selected as $2 \mathrm{~mL}$ in the following extraction process.

3.2.5. The Washing Step. The main aim of the washing step in the SPE process was to reduce interfering substances as 


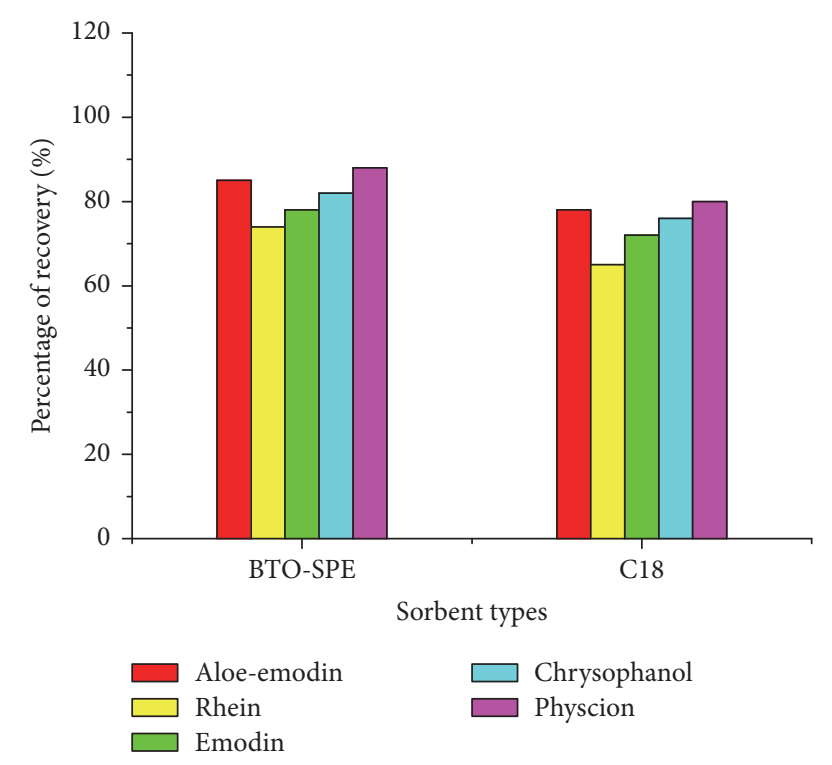

FIgure 7: Comparison of the performance of BTO-SPE with C18 sorbent.

much as possible and raise the recovery of the target analytes. In this study, the impact of washing solution (such as the composition and volume) on the extraction recoveries of target anthraquinones ( $1 \mathrm{~mL}$ urine sample spiked with $0.05 \mu \mathrm{g} \mathrm{mL}^{-1}$ working aqueous solution) was investigated. As the main interfering compounds in the human urine were watersoluble matter, different concentrations of $\mathrm{MeOH}$-water solution $(2 \mathrm{~mL})$ were employed to evaluate the effect on the recoveries of anthraquinones. The results indicated that the recoveries remained unchanged when the content of $\mathrm{MeOH}$ ranged from 2 to $5 \%$. However, with the content of $\mathrm{MeOH}$ increasing from 5 to $20 \%$, the extraction recoveries decreased gradually. To reduce interfering matter in the human urine as much as possible, $5 \% \mathrm{MeOH}$ was selected as the optimum washing solution in the following SPE process. Then, the volume of washing solution was also investigated. The results showed that highest extraction recoveries were obtained by using $2 \mathrm{~mL}$ of $5 \% \mathrm{MeOH}$ solution. Therefore, $2 \mathrm{~mL} \mathrm{5 \%} \mathrm{MeOH}$ solution was employed to wash the sample in the extraction process.

3.2.6. Comparison of SPE Cleanup between BTO-SPE and C18 Sorbent. In this section, the solid phase extraction performance of BTO-SPE sorbent with commonly available C18 cartridges was compared and investigated. To conduct the comparison, the C18 cartridges possessed the same specifications strictly as the that of homemade BTO-SPE cartridges, the SPE enrichment and cleanup procedures were manipulated as the steps previously described.

The optimized conditions were used for the extraction of target anthraquinones. As can be seen from Figure 7, by using BTO-SPE as sorbent, higher recoveries (85-96\%) of anthraquinones than those of $\mathrm{C} 18$ sorbent (recoveries were in the range of $72-80 \%$ ) were obtained. The higher recoveries by using BTO-SPE clearly demonstrated the worth of BTOSPE as a new kind of SPE sorbent. In addition to this,

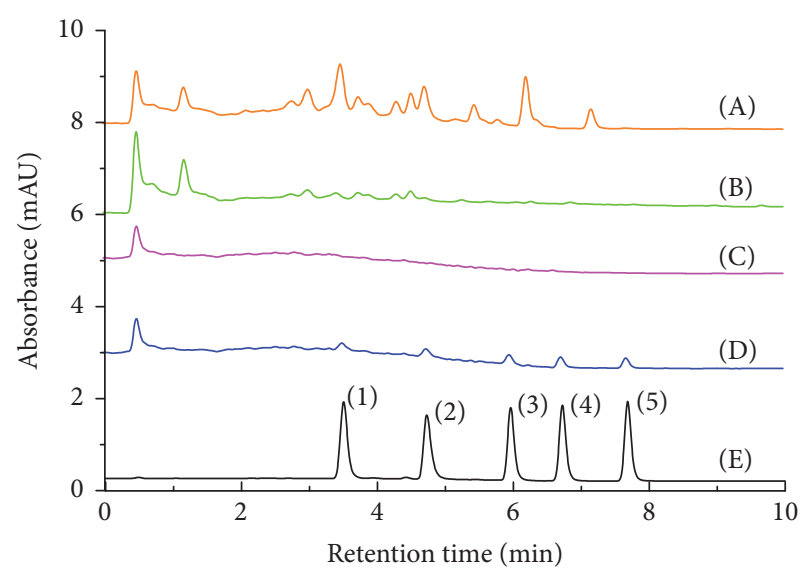

FIGURE 8: UHPLC-FLD chromatograms of samples and the standard solution: (A) blank urine sample without SPE cleanup; (B) blank urine sample after C18 SPE cleanup; (C) blank urine sample after BTO-SPE SPE cleanup; (D) urine sample spiked with $0.02 \mu \mathrm{g} \mathrm{mL} \mathrm{L}^{-1}$ standard solution of five anthraquinones; (E) standard solution of five anthraquinones $\left(0.5 \mu \mathrm{g} \mathrm{mL}^{-1}\right)$ (peaks: (1) aloeemodin; (2) rhein; (3) emodin; (4) chrysophanol; (5) physcion).

C18 sorbent shows weaker matrix removing effect in the urine sample (Figure 8(B)). The outstanding enrichment and cleanup results of BTO-SPE sorbent maybe resulted from the mixed-mode characteristic and multiple-interactions with the target analytes. This unique properties make BTO-SPE material an available sorbent material to extract trace-level anthraquinones.

3.3. Method Validation. The optimized parameters for the extraction of anthraquinones compounds by using BTOSPE as sorbents were as follows: treated urine sample $(1 \mathrm{~mL}$, $\mathrm{pH}$ 6) was loaded onto BTO-SPE sorbent $(100 \mathrm{mg})$, the cartridge was washed by using $2 \mathrm{~mL} 5 \% \mathrm{MeOH}$ solution, and then $2 \mathrm{~mL} \mathrm{MeOH}$ was applied to elute the anthraquinones fraction; the eluate was collected and evaporated to dryness at $35^{\circ} \mathrm{C}$ under a gentle stream of $\mathrm{N}_{2}$ and then redissolved into $100 \mu \mathrm{L} 0.1 \%$ phosphoric acid water/methanol solution $(50: 50, \mathrm{v} / \mathrm{v})$ prior to the UHPLC-FLD analysis. To evaluate the feasibility of the method developed, Figure 8 shows the HPLC chromatograms of blank and spiked human urine samples. All the urine samples were treated with the same SPE procedures prior to UHPLC analysis. No matrix effects, such as endogenous components or protein, were observed in urine sample chromatogram, indicating excellent specificity for the determination of anthraquinones in human urine.

Under the optimized conditions, the proposed method was investigated by evaluating the linear curves, limits of detection (LODs), and other characteristics. As shown in Table 1, all analytes exhibited good linearity from 0.012 to $1.800 \mu \mathrm{g} \mathrm{mL}^{-1}$ with correlation coefficients $\left(r^{2}\right)$ ranging from 0.9993 to 0.9997 . The LODs were in the range of 3.9-5.7 $\mathrm{ng} \mathrm{mL}^{-1}$ based on a signal-to-noise ratio of 3 , while the limits of quantification (LOQs) were in the range of 12.0$18.2 \mathrm{ng} \mathrm{mL}^{-1}$ based the ratio of signal-to-noise of 10 . The relative standard deviations (RSDs) of peak area and retention 
TABLE 1: Analytical performance data of the proposed method.

\begin{tabular}{|c|c|c|c|c|c|c|c|}
\hline \multirow{2}{*}{ Analyte } & \multirow{2}{*}{ Calibration curves } & \multirow{2}{*}{$r^{2}$} & \multirow{2}{*}{$\begin{array}{c}\text { Linear range } \\
\mu \mathrm{g} \mathrm{mL}^{-1}\end{array}$} & \multirow{2}{*}{$\begin{array}{c}\text { LOD } \\
\text { ng mL }^{-1}\end{array}$} & \multirow{2}{*}{$\begin{array}{c}\text { LOQ } \\
\text { ng mL }\end{array}$} & \multicolumn{2}{|c|}{$\operatorname{RSD}(\%, n=3)$} \\
\hline & & & & & & Peak area & Retention time \\
\hline Aloe-emodin & $y=10.67 x-0.012$ & 0.9997 & $0.012-1.200$ & 4.1 & 12.1 & 2.35 & 0.38 \\
\hline Rhein & $y=9.14 x-0.020$ & 0.9995 & $0.018-1.800$ & 5.7 & 18.2 & 2.21 & 0.42 \\
\hline Emodin & $y=9.66 x-0.011$ & 0.9996 & $0.015-1.500$ & 5.1 & 15.2 & 1.84 & 0.29 \\
\hline Chrysophanol & $y=10.48 x-0.016$ & 0.9993 & $0.012-1.200$ & 3.9 & 12.0 & 2.48 & 0.26 \\
\hline Physcion & $y=9.55 x-0.012$ & 0.9996 & $0.013-1.300$ & 4.4 & 13.1 & 3.05 & 0.22 \\
\hline
\end{tabular}

TABLE 2: The interday and intraday precision and recoveries of the method.

\begin{tabular}{|c|c|c|c|c|c|}
\hline \multirow{2}{*}{ Analytes } & \multirow{2}{*}{ Spiked amount (ng/g) } & \multicolumn{2}{|c|}{ Intraday $(n=3)$} & \multicolumn{2}{|c|}{ Interday $(n=3)$} \\
\hline & & Recovery (\%) & RSD (\%) & Recovery (\%) & RSD (\%) \\
\hline \multirow{3}{*}{ Aloe-emodin } & 20 & 97.3 & 2.26 & 96.7 & 2.88 \\
\hline & 100 & 96.8 & 2.58 & 97.5 & 3.15 \\
\hline & 500 & 95.2 & 2.42 & 94.8 & 3.36 \\
\hline \multirow{3}{*}{ Rhein } & 20 & 104.3 & 2.03 & 102.8 & 3.28 \\
\hline & 100 & 97.5 & 2.83 & 98.1 & 2.95 \\
\hline & 500 & 96.3 & 2.78 & 97.4 & 3.45 \\
\hline \multirow{3}{*}{ Emodin } & 20 & 105.6 & 2.75 & 106.6 & 3.47 \\
\hline & 100 & 96.7 & 2.63 & 95.8 & 4.58 \\
\hline & 500 & 94.9 & 2.86 & 95.4 & 3.48 \\
\hline \multirow{3}{*}{ Chrysophanol } & 20 & 97.7 & 2.05 & 98.0 & 2.85 \\
\hline & 100 & 98.3 & 2.83 & 97.7 & 3.15 \\
\hline & 500 & 95.8 & 2.75 & 96.2 & 3.42 \\
\hline \multirow{3}{*}{ Physcion } & 20 & 104.6 & 2.46 & 105.6 & 4.03 \\
\hline & 100 & 95.8 & 2.94 & 96.3 & 3.85 \\
\hline & 500 & 96.8 & 2.81 & 96.4 & 3.07 \\
\hline
\end{tabular}

time were in the range of $1.84-3.05 \%$ and $0.22-0.42 \%$, respectively. These excellent results suggested that the proposed method was applicable to determine trace-level anthraquinones in human urine.

The intraday and interday precision of this SPE-UPLCFLD method was investigated by testing three spiked urine samples at different concentration levels (20, 100, and $500 \mathrm{ng} \mathrm{g}^{-1}$ ) in accordance with the whole extraction process described above. The intraday precision of the assay was assessed by analyzing anthraquinones in spiked samples three replicates in the same day, while the interday precision was performed on three consecutive days using the optimized assay conditions. As shown in Table 2, the relative standard deviations (RSDs) of interday and intraday analysis were in the range of $2.85-4.58 \%$ and $2.03-2.94 \%$, respectively. All these data are showing good feasibility as a bioanalytical method.

The recovery of the method was assessed by using blank urine spiked at concentrations of high, medium, and low concentrations for each analyte. The recoveries of anthraquinones were determined and shown in Table 2, which ranged from 94.8 to $106.6 \%$. Thus, the developed UHPLC method based on BTO-SPE is suitable for analyzing the anthraquinones in biological samples.
3.4. Real Human Urine Sample Analysis. The proposed means were used for the determination of anthraquinones in urine from five patients with cerebral traumatic injury after oral rhubarb decoction. The typical chromatograms of human urine on BTO-SPE cartridge were shown in Figure 8, showing that anthraquinones obtained better separation from the sample matrixes. The contents of anthraquinones in the decoction were determined by UHPLC-FLD, which were $17.50 \pm 0.94,105.12 \pm 2.14,47.90 \pm 1.39,58.98 \pm 1.26$, and $29.15 \pm 1.82 \mu \mathrm{g} \mathrm{mL}^{-1}$ for chrysophanol, rhein, emodin, aloeemodin, and physcion, respectively. The $36 \mathrm{~h}$ urine samples were collected after taking rhubarb decoction orally at the dosage of $0.05 \mathrm{~g} / \mathrm{kg}$. This experiment has been approved by the medical ethics committee of Henan University of Chinese Medicine, and the informed consent was signed before the experiment. Pretreatment of $1 \mathrm{~mL}$ urine sample was carried out according to the optimized procedure, the concentration of anthraquinones was analyzed, and the results are shown in Table 3. The recoveries of anthraquinones were determined by spiking the anthraquinones of $100 \mathrm{ng} \mathrm{mL}^{-1}$, and their recoveries ranged from 95.4 to $104.5 \%$, indicating that the proposed UHPLC-FLD method based on BTO-SPE was appropriate for the analysis of anthraquinones in human urine. 
TABLE 3: Determination of anthraquinones in urine from five patients after oral rhubarb decoction.

\begin{tabular}{|c|c|c|c|c|c|}
\hline Sample number & Aloe-emodin & Rhein & $\begin{array}{l}\text { Emodin } \\
\qquad \mu \mathrm{g} \mathrm{mL}^{-1}\end{array}$ & Chrysophanol & Physcion \\
\hline (1) & 0.078 & 0.662 & 0.047 & 0.152 & 0.038 \\
\hline (2) & 0.054 & 0.782 & 0.032 & 0.236 & 0.027 \\
\hline (3) & 0.068 & 0.715 & 0.038 & 0.132 & 0.038 \\
\hline (4) & 0.062 & 0.813 & 0.071 & 0.086 & 0.034 \\
\hline (5) & 0.085 & 0.764 & 0.058 & 0.124 & 0.056 \\
\hline
\end{tabular}

TABLE 4: Comparison of BTO-SPE-FLD method with other methods for the determination of anthraquinones.

\begin{tabular}{|c|c|c|c|c|c|c|}
\hline Clean-up & $\begin{array}{c}\text { Determination } \\
\text { technique }\end{array}$ & $\begin{array}{l}\text { Linearity } \\
\left(\mu \mathrm{g} \mathrm{mL}^{-1}\right)\end{array}$ & Recoveries (\%) & $\begin{array}{c}\text { RSD } \\
(\%) \\
\end{array}$ & $\begin{array}{c}\mathrm{LOD} \\
\left(\mu \mathrm{g} \mathrm{mL}^{-1}\right)\end{array}$ & References \\
\hline HLB-SPE & $\mathrm{MEKC}^{\mathrm{a}}$ & $5-50$ & 98-107 & $<2.55$ & $0.50-0.58$ & [11] \\
\hline C18-SPE & HPLC-FLD & $0.0210-19.52$ & $94.2-110.4$ & $<7.4$ & $0.007-0.0133$ & {$[13]$} \\
\hline MIP-MSPD ${ }^{\mathrm{b}}$ & HPLC-UV & $1-200$ & $91.2-101.4$ & $5.3-7.1$ & $0.23-0.28$ & {$[17]$} \\
\hline Soxhlet extraction & CD-MEKC & $3.86-85$ & $91.1-100.08$ & $1.12-2.01$ & $0.75-1.15$ & [19] \\
\hline BTO-SPE & UHPLC-FLD & $0.012-1.8$ & $94.9-105.6$ & $2.03-2.86$ & $0.0039-0.0057$ & $\begin{array}{l}\text { This } \\
\text { method }\end{array}$ \\
\hline
\end{tabular}

${ }^{a}$ micellar electrokinetic chromatography; ${ }^{b}$ molecularly imprinted polymer-matrix solid-phase dispersion; ${ }^{c}$ cyclodextrin-modified micellar electrokinetic chromatography.

The developed method was compared with the reported methods for the analysis of anthraquinones in biological or herbal medicine samples. As summarized in Table 4, the BTO-SPE-FLD method provided higher recoveries and lower LODs, than $[11,13,17,19]$, which was ascribed to the contribution of the mixed-mode and multiple-interactions BTOSPE materials. In addition to that, the method developed also showed satisfactory linearity and equivalent or lower RSDs and LODs values.

\section{Conclusion}

In this study, a UHPLC-FLD method has been proposed for the simultaneous analysis of five trace-level anthraquinones in human urine by using BTO-SPE as sorbent. With the optimal sample pretreatment condition, the method was successfully applied to urine samples from 5 patients. Comparative study showed BTO-SPE sorbent had excellent cleanup and enrichment property of anthraquinones due to its multiinteraction ability. The extraction process probably was regulated by multiple-interactions, including hydrophobic, hydrogen bonding, dipole-dipole, and $\pi-\pi$ interactions. The proposed UHPLC-FLD method based on BTO-SPE is promising for the determination of anthraquinones in biological samples.

\section{Conflicts of Interest}

The authors declare that they have no conflicts of interest.

\section{Acknowledgments}

The authors acknowledge the support of Doctoral Research Fund of Henan University of TCM (BSJJ2014-09) and Provincial Universities Basic Scientific Research Fund of Henan University of TCM (2014KYYWF-QN05).

\section{References}

[1] J. Wang, H. Zhao, W. Kong et al., "Microcalorimetric assay on the antimicrobial property of five hydroxyanthraquinone derivatives in rhubarb (Rheum palmatum L.) to Bifidobacterium adolescentis," Phytomedicine, vol. 17, no. 8-9, pp. 684-689, 2010.

[2] C.-Y. Hsiang, C.-L. Hsieh, S.-L. Wu, L. Lu, T.-Y. Lai, and Ho, "Inhibitory effect of anti-pyretic and anti-inflammatory herbs on herpes simplex virus replication," American Journal of Chinese Medicine, vol. 29, no. 3-4, pp. 459-467, 2001.

[3] S. K. Agarwal, S. S. Singh, S. Verma, and S. Kumar, "Antifungal activity of anthraquinone derivatives from Rheum emodi," Journal of Ethnopharmacology, vol. 72, no. 1-2, pp. 43-46, 2000.

[4] A. Iizuka, O. T. Iijima, K. Kondo et al., "Evaluation of Rhubarb using antioxidative activity as an index of pharmacological usefulness," Journal of Ethnopharmacology, vol. 91, no. 1, pp. 8994, 2004.

[5] Y. Liu, F. Yan, Y. Liu et al., "Aqueous extract of rhubarb stabilizes vulnerable atherosclerotic plaques due to depression of inflammation and lipid accumulation," Phytotherapy Research, vol. 22, no. 7, pp. 935-942, 2008.

[6] Q. Huang, G. Lu, H. Shen, M. C. M. Chung, and N. O. Choon, "Anti-cancer properties of anthraquinones from rhubarb," Medicinal Research Reviews, vol. 27, no. 5, pp. 609-630, 2007. 
[7] K. Tian, Y. Wang, Y. Chen, X. Chen, and Z. Hu, "Application of 1alkyl-3-methylimidazolium-based ionic liquids as background electrolyte in capillary zone electrophoresis for the simultaneous determination of five anthraquinones in Rhubarb," Talanta, vol. 72, no. 2, pp. 587-593, 2007.

[8] H. Lü, J. Wang, X. Wang, X. Lin, X. Wu, and Z. Xie, "Rapid separation and determination of structurally related anthraquinones in Rhubarb by pressurized capillary electrochromatography," Journal of Pharmaceutical and Biomedical Analysis, vol. 43, no. 1, pp. 352-357, 2007.

[9] N. P. Singh, A. P. Gupta, A. K. Sinha, and P. S. Ahuja, "High-performance thin layer chromatography method for quantitative determination of four major anthraquinone derivatives in Rheum emodi," Journal of Chromatography A, vol. 1077, no. 2, pp. 202-206, 2005.

[10] L.-C. Chang and S.-W. Sun, "Micellar electrokinetic chromatography for separation of a mixture of coptis alkaloids, scute flavonoids, and rhubarb anthraquinones and bianthrones," Journal of Pharmaceutical and Biomedical Analysis, vol. 40, no. 1, pp. 62-67, 2006.

[11] C.-H. Kuo and S.-W. Sun, "Analysis of nine rhubarb anthraquinones and bianthrones by micellar electrokinetic chromatography using experimental design," Analytica Chimica Acta, vol. 482, no. 1, pp. 47-58, 2003.

[12] S.-Y. Wei, W.-X. Yao, W.-Y. Ji, J.-Q. Wei, and S.-Q. Peng, "Qualitative and quantitative analysis of anthraquinones in rhubarbs by high performance liquid chromatography with diode array detector and mass spectrometry," Food Chemistry, vol. 141, no. 3, pp. 1710-1715, 2013.

[13] S.-X. Feng, J.-S. Li, L.-B. Qu, Y.-M. Shi, and D. Zhao, "Comparative pharmacokinetics of five rhubarb anthraquinones in normal and thrombotic focal cerebral ischemia-induced rats," Phytotherapy Research, vol. 27, no. 10, pp. 1489-1494, 2013.

[14] S. Wang, P. Chen, Y. Xu, X. Li, and X. Fan, "Characterization of the chemical constituents in Da-Huang-Gan-Cao-Tang by liquid chromatography coupled with quadrupole time-of-flight tandem mass spectrometry and liquid chromatography coupled with ion trap mass spectrometry," Journal of Separation Science, vol. 37, no. 14, pp. 1748-1761, 2014.

[15] M. Wang, Y. Li, Y. Huang, Y. Tian, F. Xu, and Z. Zhang, "Chemomic and chemometric approach based on ultra-fast liquid chromatography with ion trap time-of-flight mass spectrometry to reveal the difference in the chemical composition between Da-Cheng-Qi decoction and its three constitutional herbal medicines," Journal of Separation Science, vol. 37, no. 9-10, pp. 1148-1154, 2014.

[16] M. Wang, J. Fu, M. Lv et al., "Effect of wine processing and acute blood stasis on the serum pharmacochemistry of rhubarb: A possible explanation for processing mechanism," Journal of Separation Science, vol. 37, no. 18, pp. 2499-2503, 2014.

[17] Y. Hong and L. Chen, "Extraction of Anthraquinones from Rhubarb by a Molecularly Imprinted-Matrix Solid-Phase Dispersion Method with HPLC Detection," Analytical Letters, vol. 46, no. 14, pp. 2235-2252, 2013.

[18] X. Wu, S. Liang, X. Ge, Y. Lv, and H. Sun, "Synthesis and evaluation of dummy molecularly imprinted microspheres for the specific solid-phase extraction of six anthraquinones from slimming tea," Journal of Separation Science, vol. 38, no. 8, pp. 12631270, 2015.

[19] X. Shang and Z. Yuan, "Determination of six components in Rhubarb by cyclodextrin-modified micellar electrokinetic chromatography using a mixed micellar system of sodium cholate and sodium taurocholate," Analytica Chimica Acta, vol. 456, no. 2, pp. 183-188, 2002.

[20] S.-W. Sun and P.-C. Yeh, "Analysis of rhubarb anthraquinones and bianthrones by microemulsion electrokinetic chromatography," Journal of Pharmaceutical and Biomedical Analysis, vol. 36, no. 5, pp. 995-1001, 2005.

[21] T. Chen, Y. Liu, D. Zou et al., "Application of an efficient strategy based on liquid-liquid extraction, high-speed counter-current chromatography, and preparative HPLC for the rapid enrichment, separation, and purification of four anthraquinones from Rheum tanguticum," Journal of Separation Science, vol. 37, no. 1-2, pp. 165-170, 2014.

[22] C. Lu, H. Wang, W. Lv et al., "Ionic liquid-based ultrasonic/ microwave-assisted extraction combined with UPLC for the determination of anthraquinones in rhubarb," Chromatographia, vol. 74, no. 1-2, pp. 139-144, 2011.

[23] K. Hu, J. Liu, C. Tang et al., "Preparation, characterization and application of a new 25,27-bis-[2-(5- methylthiadiazole)thioethoxyl]-26,28-dihydroxy-para-tert-butyl calix[4]arene stationary phase for HPLC," Journal of Separation Science, vol. 35, no. 2, pp. 239-247, 2012.

[24] K. Hu, Y. Zhang, J. Liu et al., "Development and application of a new 25,27-bis(1-phenylalaninemethylester-N-carbonylmethoxy)-26,28-dihydroxy-para-tert-butylcalix[4]arene stationary phase," Journal of Separation Science, vol. 36, no. 3, pp. 445-453, 2013.

[25] M. Śliwka-Kaszyńska and M. Ślebioda, "Polycyclic aromatic hydrocarbons as test probes to investigate the retention behavior of 1,3-alternate calix[4] arene silica-bonded stationary phases," Journal of Separation Science, vol. 37, no. 5, pp. 543-550, 2014.

[26] C. Ding, K. Qu, Y. Li et al., "Preparation and characterization of six calixarene bonded stationary phases for high performance liquid chromatography," Journal of Chromatography A, vol. 1170, no. 1-2, pp. 73-81, 2007.

[27] T. Sokoließ, U. Menyes, U. Roth, and T. Jira, "New calixarenebonded stationary phases in high-performance liquid chromatography: Comparative studies on the retention behavior and on influences of the eluent," Journal of Chromatography A, vol. 898, no. 1, pp. 35-52, 2000.

[28] S. K. T. Chelvi, J. Zhao, L. Chen et al., "Preparation and characterization of 4 -isopropylcalix[4]arene-capped (3-(2-O- $\beta$ cyclodextrin)-2-hydroxypropoxy)-propylsilyl-appended silica particles as chiral stationary phase for high-performance liquid chromatography," Journal of Chromatography A, vol. 1324, pp. 104-108, 2014.

[29] J. Lu, W. Zhang, Y. Zhang et al., "A new stationary phase for high performance liquid chromatography: Calix[4] arene derivatized chitosan bonded silica gel," Journal of Chromatography A, vol. 1350, pp. 61-67, 2014.

[30] K. Hu, Z. Deng, B. Wang et al., "Development of a decaazacyclophane stationary phase for high-performance liquid chromatography," Journal of Separation Science, vol. 38, no. 1, pp. 6066, 2015.

[31] K. Hu, W. Zhang, H. Yang et al., "Calixarene ionic liquid modified silica gel: a novel stationary phase for mixed-mode chromatography," Talanta, vol. 152, pp. 392-400, 2016.

[32] M. Wang, "Nitrogen and oxygen bridged calixaromatics: synthesis, structure, functionalization, and molecular recognition," Accounts of Chemical Research, vol. 45, no. 2, pp. 182-195, 2012.

[33] K. Hu, S. Feng, M. Wu et al., "Development of a V-shape bis(tetraoxacalix[2] arene[2]triazine) stationary phase for High 
performance liquid chromatography," Talanta, vol. 130, pp. 6370, 2014.

[34] K. Hu, Z. Deng, S. Li, M. Wu, W. Liu, and S. Zhang, "SPEUHPLC-DAD method for the simultaneous determination of three flavonoids in grape juice by using bis(tetraoxacalix[2] arene[2] triazine)-modified silica as sorbent," Food Analytical Methods, vol. 10, no. 10, pp. 3434-3442, 2017. 

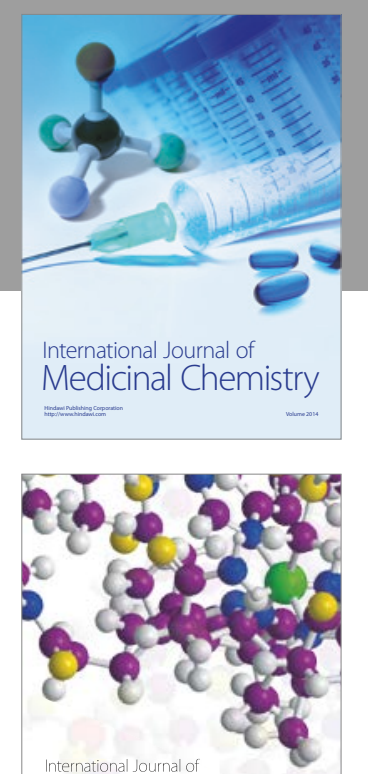

Carbohydrate Chemistry

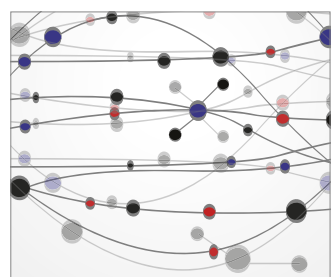

The Scientific World Journal
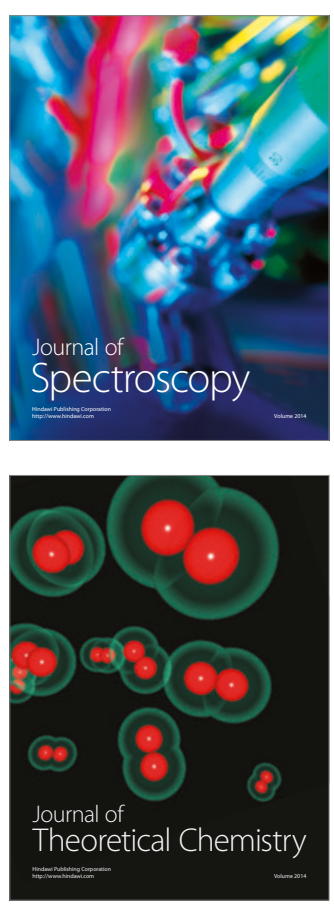
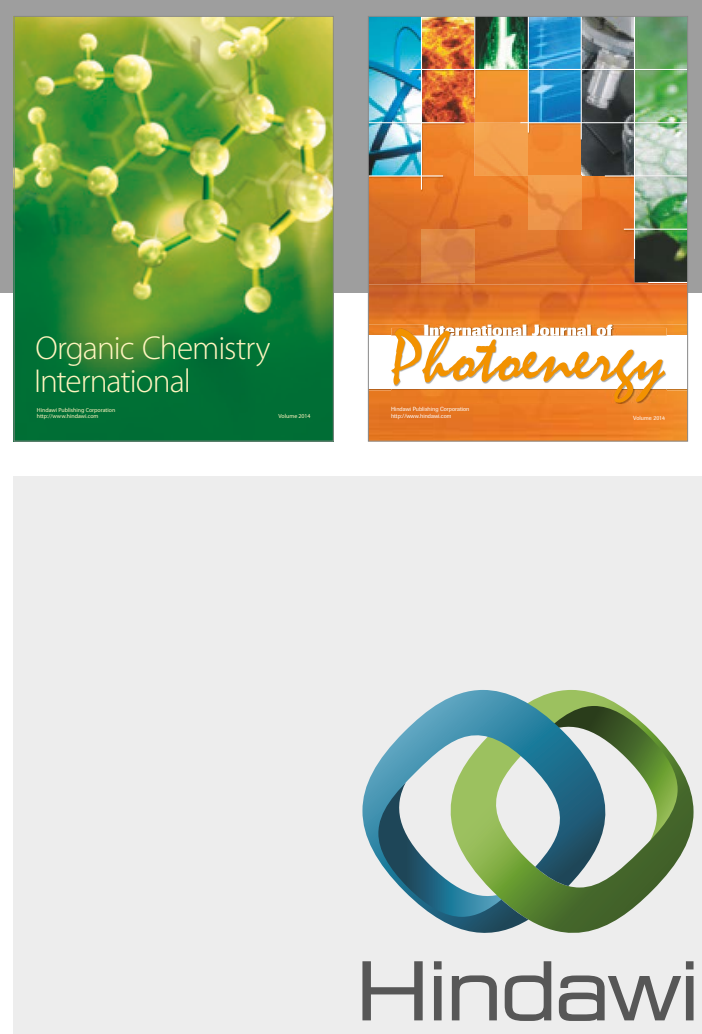

Submit your manuscripts at

https://www.hindawi.com

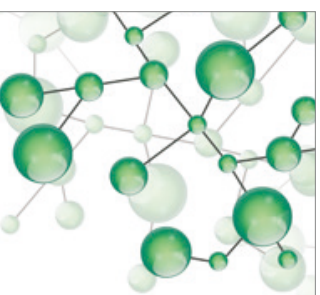

International Journal of

Inorganic Chemistry

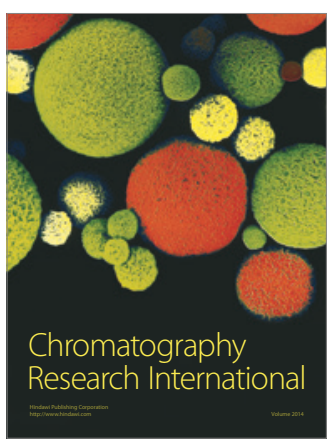

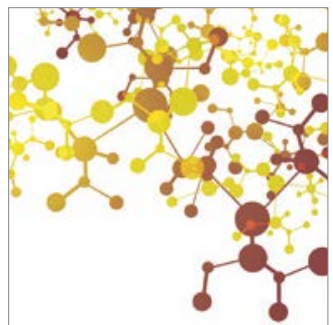

Applied Chemistry
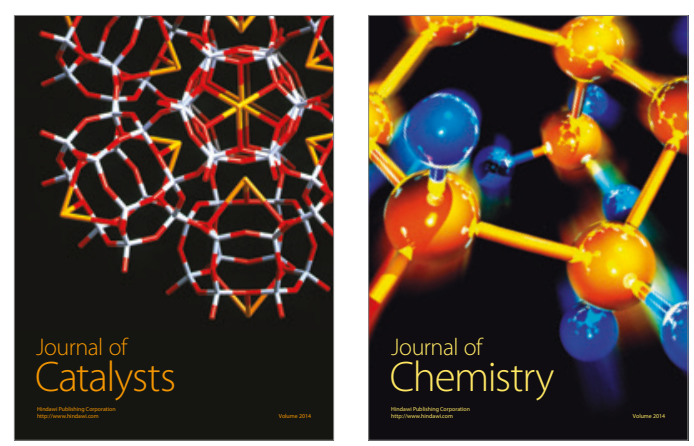
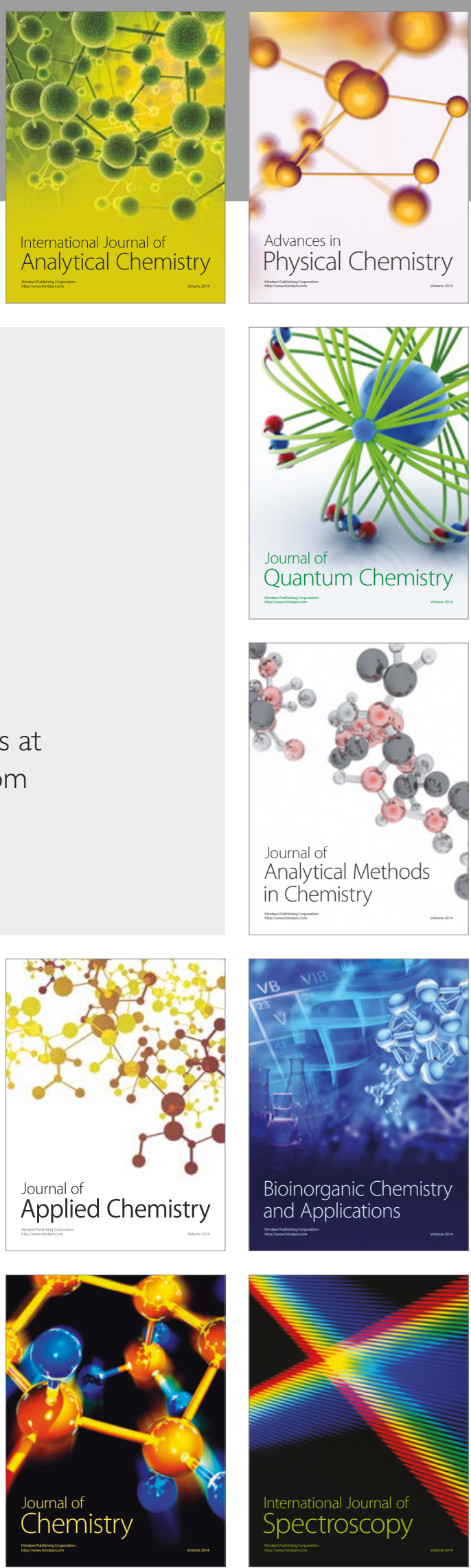